\title{
Erratum to "On the Convergence of Implicit Iterative Processes for Asymptotically Pseudocontractive Mappings in the Intermediate Sense"
}

\author{
Xiaolong Qin, ${ }^{1}$ Jong Kyu Kim, ${ }^{2}$ and Tianze Wang ${ }^{3}$ \\ ${ }^{1}$ Department of Mathematics, Hangzhou Normal University, Hangzhou 310036, China \\ 2 Department of Mathematics, Kyungnam University, Masan 631-701, Republic of Korea \\ ${ }^{3}$ School of Mathematics and Information Sciences, North China University of Water Resources and Electric \\ Power, Zhengzhou 450011, China
}

Correspondence should be addressed to Xiaolong Qin, lijhqxl@yahoo.com.cn

Received 27 May 2012; Accepted 28 May 2012

Copyright (C) 2012 Xiaolong Qin et al. This is an open access article distributed under the Creative Commons Attribution License, which permits unrestricted use, distribution, and reproduction in any medium, provided the original work is properly cited.

The first author of the above-mentioned paper regrets that the paper was published with the wrong address. The corrected address of the first author is given as above. 


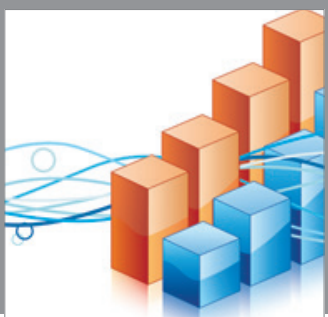

Advances in

Operations Research

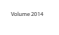

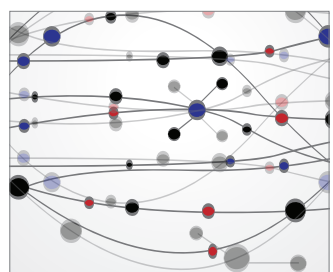

\section{The Scientific} World Journal
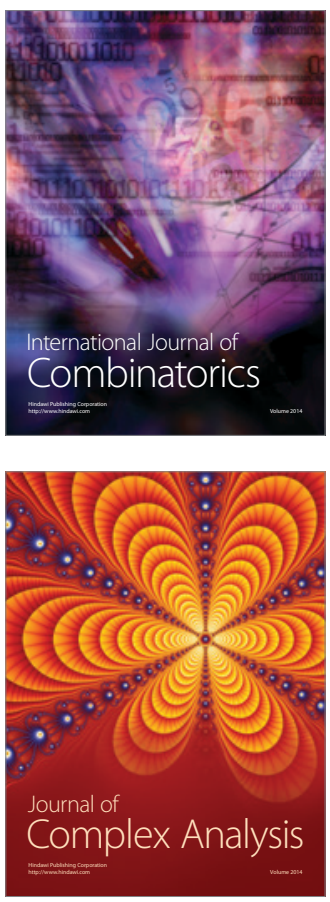

International Journal of

Mathematics and

Mathematical

Sciences
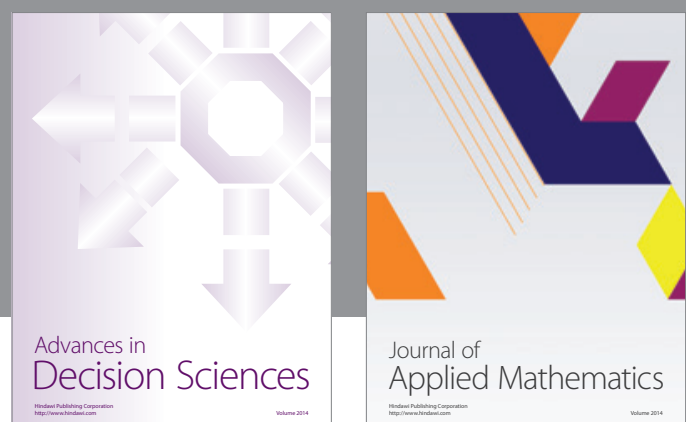

Journal of

Applied Mathematics
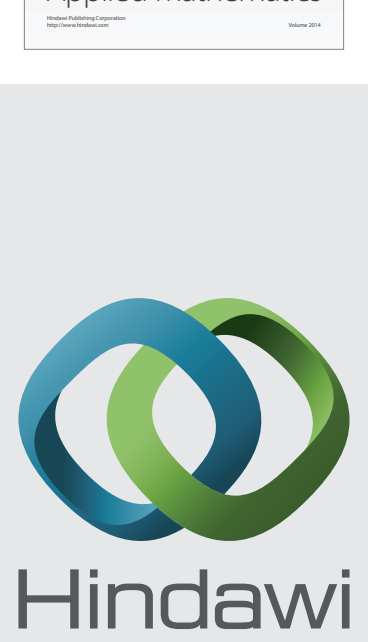

Submit your manuscripts at http://www.hindawi.com
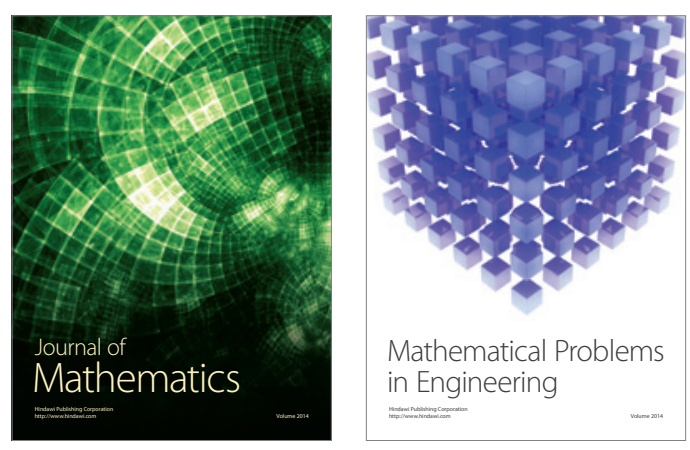

Mathematical Problems in Engineering
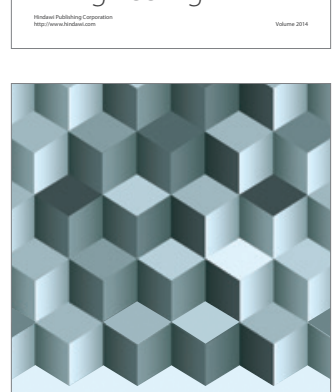

Journal of

Function Spaces
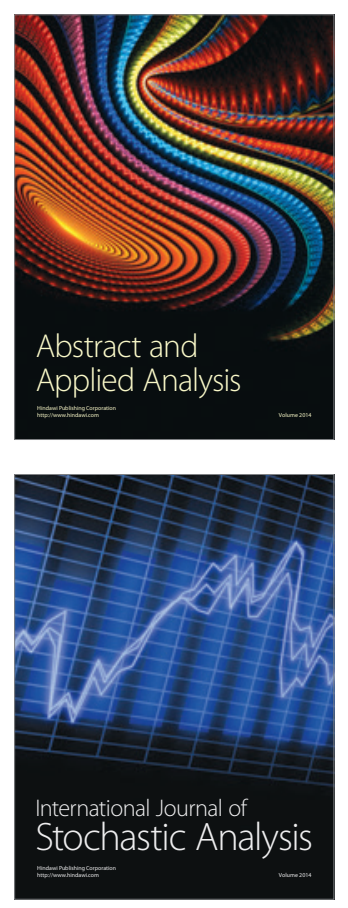

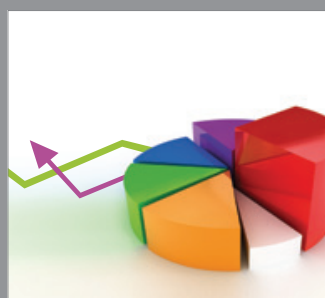

ournal of

Probability and Statistics

Promensencen
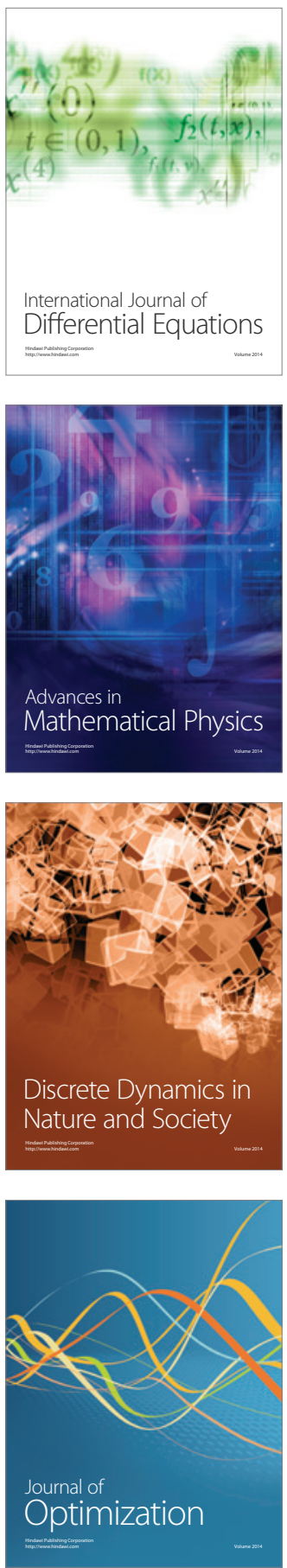